\title{
Delayed immediate surgery for orbital floor fractures: Less can be more
}

\author{
David T Tang MD, Jan F Lalonde RN, Donald H Lalonde MD
}

\begin{abstract}
DT Tang, JF Lalonde, DH Lalonde. Delayed immediate surgery for orbital floor fractures: Less can be more. Can J Plast Surg
\end{abstract} 2011;19(4):125-128.

Orbital floor fractures can result in diplopia, enophthalmos, hypoglobus and infraorbital dysthesia. Currently, the most common treatment for orbital floor fractures is immediate surgical intervention. However, there are a number of well-documented cases of unoperated orbital floor fractures in the literature, culminating in diplopia or enophthalmos in few patients. Of these, none reported the diplopia or enophthalmos to be bothersome. As reported previously in the ophthalmology literature, most orbital floor fracture-induced diplopia resolves as the swelling settles, and the few patients with remaining diplopia can successfully be treated with surgery on the uninvolved eye. It has also been commented that most patients with enophthalmos are asymptomatic. The authors' institution has more than 50 surgeon-years experience with delaying immediate surgery for two weeks to allow time for the swelling-induced diplopia to resolve. In the authors' experience, true entrapment of the inferior rectus muscle is rare. The present article describes a study of late follow-up (average 945 days) of 11 nonoperated patients with orbital floor fractures. In the eight patients who initially presented with diplopia, there was resolution of functionally limiting double vision. Only one patient had asymptomatic, but measurably significant, enophthalmos at $-3 \mathrm{~mm}$. All patients had full restoration of extraocular movements and resolution of infraorbital dysthesia. None of the patients were exposed to the operative risks of ectropion, infection, implant extrusion, bleeding or blindness. The present study provides level IV evidence that delaying surgery up to two weeks after orbital floor fracture may avoid unnecessary surgical risks and inconveniences in many patients with orbital floor fracture.

Key Words: Blowout; Diplopia; Enopthalmos; Orbital floor

$\mathrm{O}$ rbital floor fractures are a not infrequent consequence of facial trauma. Common etiologies for these injuries include motor vehicle accidents $(1,2)$ and violent altercations $(3,4)$. The majority of these fractures are sustained by young male patients $(5-7)$. Recognized clinical effects of orbital floor fractures include diplopia, impaired extraocular muscle motility, enophthalmos, hypoglobus and infraorbital dysthesia.

In 1957, Smith (8) espoused early exploration and reconstruction of the orbital floor using bone graft implants. In 1971, Emery et al (9) documented the natural history of untreated orbital floor fractures. This was closely followed by a recommendation from Putterman (10) to delay surgery because there was no advantage to early surgery and, in many patients, the diplopia resolved as the swelling reduced.

At Saint John Regional Hosptial, Saint John, New Brunswick, we have more than 50 surgeon-years of experience with delayed orbital floor fracture surgery. If a forced duction test is negative for true entrapment of the inferior rectus, we wait up to two weeks to see if diplopia resolves, or if symptomatic enophthalmos of more than $2 \mathrm{~mm}$ develops. We operate for the latter condition, or for diplopia that persists at two weeks. We have observed that diplopia resolves in most patients because it is caused by swelling. We also note that mild (less than $2 \mathrm{~mm}$ ) enophthalmos is usually asymptomatic. Our observations are supported by previous studies examining nonoperatively managed patients $(11,12)$.

\section{Le report de la chirurgie immédiate en cas de fractures du plancher orbitaire : lorsque le mieux est l'ennemi du bien}

Les fractures du plancher orbitaire peuvent provoquer une diplopie, un eénophtalmie, un hypoglobe et une dysesthésie de la région infraorbitaire. Une intervention chirurgicale immédiate en constitue le principal traitement. Cependant, on trouve plusieurs cas bien documentés de fractures du plancher orbitaire non opérées dans les publications scientifiques, lesquelles ont suscité une diplopie ou une énophtalmie chez quelques patients. Aucun d'entre eux n'a déclaré trouver la diplopie ou l'énophtalmie dérangeante. Comme l'indiquent les publications en ophtalmologie, la plupart des diplopies induites par une fracture du plancher orbitaire se résorbent à mesure que l'œdème disparaît, et les quelques patients qui conservent une diplopie peuvent être traités avec succès par une opération de l'œil non atteint. Il est également précisé que la plupart des patients présentant une énophtalmie sont asymptomatiques. Leétablissement des auteurs compte plus de 50 chirurgiens-année d'expérience à reporter la chirurgie immédiate de deux semaines afin de permettre à l'œedème imputable à la diplopie de se résorber. D'après l'expérience des auteurs, il est rare de constater une véritable incarcération du muscle droit inférieur. Le présent article expose une étude du suivi tardif (moyenne de 945 jours) de 11 patients non opérés après une fracture du plancher non orbitaire. Chez les huit patients qui présentaient une diplopie au départ, on a constaté une résolution de la vision double responsable d'une limitation fonctionnelle. Un seul patient présentait une énophtalmie asymptomatique mais mesurable et significative de $-3 \mathrm{~mm}$. Tous les patients ont constaté le rétablissement complet de leurs mouvements extraoculaires et la résolution de leur dysesthésie infraorbitaire. Aucun n'a été exposé aux risques opératoires d'ectropion, d'infection, d'extrusion des implants, de saignements ou de cécité. La présente étude fournit des données probantes de niveau IV selon lesquelles le report de l'opération jusqu'à deux semaines après la fracture du plancher orbitaire pourrait éviter des risques et inconvénients chirurgicaux inutiles pour de nombreux patients.

The purpose of the present article is to document our experience, which parallels that of Putterman. We believe that our approach has avoided unnecessary surgical and anesthetic risks for hundreds of patients, as well as unnecessary operating room time and costs.

\section{METHODS}

After ethics review board approval, a 10-year review (January 1999 to December 2008) of medical records, clinical notes, radiographs and computed tomography (CT) scans in patients with orbital floor fractures managed by one senior surgeon (DHL) at the Saint John Regional Hospital was performed. Data regarding patient demographics, fracture etiology, presenting signs and symptoms, and subsequent follow-up visits assessing resolution or persistence of ophthalmic dysfunction were collected.

Inclusion criteria were patients 16 years of age or older with orbital floor fracture confirmed either by radiograph or CT. Patients were excluded from the study if they had bilateral orbital floor fractures, previous orbital fractures, pre-existing ophthalmic dysfunction, significant concomitant orbital/facial fractures, reinjury before current follow-up assessment, or an inability to appropriately undergo follow-up assessment.

Once the appropriate patients were identified, they were contacted and either interviewed by telephone or invited to return to the hospital for formal clinical assessment. The clinical outcomes recorded

Division of Plastic and Reconstructive Surgery, Dalhousie University, Saint John, New Brunswick

Correspondence: Dr Donald H Lalonde, Division of Plastic and Reconstructive Surgery, Dalhousie University, Hilyard Place, Suite A280,

560 Main Street, Saint John, New Brunswick E2K 1J5. Telephone 506-648-7950, fax 506-652-8042, e-mail drdonlalonde@nb.aibn.com 


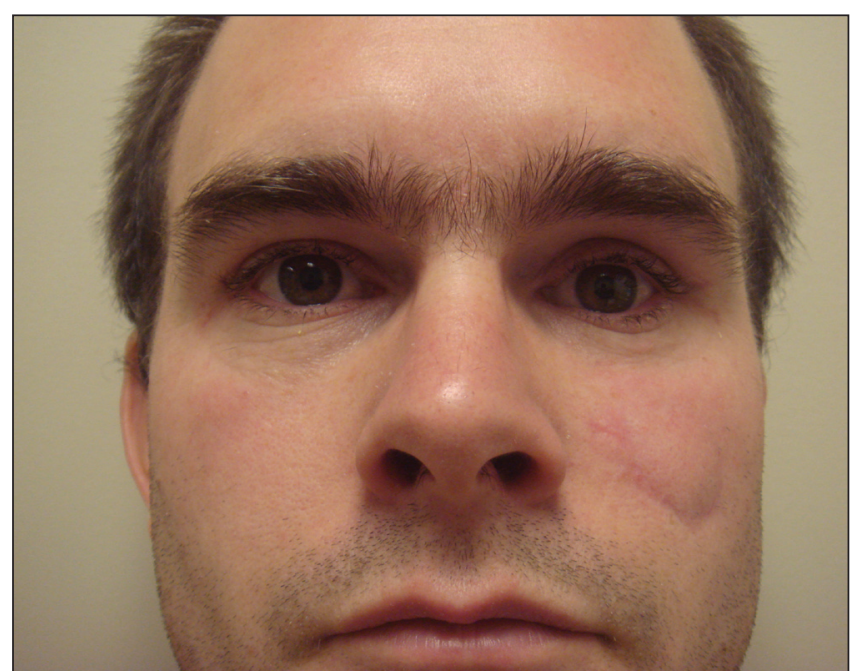

Figure 1) Asymptomatic enophthalmos of the left eye measured at $-3 \mathrm{~mm}$ relative to the right eye three years after orbital floor fracture

included diplopia (with clarification of the presence of double vision in peripheral or central gaze), asymmetric extraocular motility, enophthalmos, ectropion and sensory disturbance in the infraorbital nerve distribution. In patients who were examined in the clinic, enophthalmos was measured with a Hertel exophthalmometer (Richmond Products Inc, USA) and was considered significant if there was a greater than $2 \mathrm{~mm}$ difference relative to the contralateral side. In addition to historical and physical assessment, photographs and video of extraocular movement were obtained for each patient seen. Patients who underwent CT imaging at the time of their initial injury were asked to undergo a repeat scan.

\section{RESULTS}

Over the 10-year study period, 21 patients with orbital floor fractures and who met the inclusion criteria were identified. Two of the 21 patients had concomitant nasal bone fractures that did not preclude their enrollment in the study. Two patients were excluded from the study due to bilateral orbital floor fractures. One patient was excluded for significant concomitant maxillary fracture. Seven patients were excluded because they were unable complete adequate follow-up. In total, 11 patients were able to attend the clinic for a complete physical examination and were included in the present study.

Eighty-two per cent of the patients were male. The average age was 33 years, with a range of 17 to 54 years. The most common etiology for orbital floor fractures in this sample population was sports-related injuries, followed by motor vehicle accidents, falls and altercations. The average time from initial injury to final clinical assessment was 945 days, with a range of 47 to 1168 days.

On initial presentation, $73 \%$ of the patients had diplopia, $45 \%$ demonstrated decreased extraocular movements, $18 \%$ had enophthalmos and $82 \%$ experienced infraorbital numbness. At the time of late follow-up, only one patient had persistent diplopia and it was on extreme lateral gaze only. This was not a functional problem for this patient. Another patient had clinically visible enophthalmos measuring $-3 \mathrm{~mm}$ relative to the contralateral side, but this in no way bothered the patient (Figure 1). All patients demonstrated complete extraocular movements (including the patient in Figure 1) and full resolution of infraorbital dysthesia (Figure 2). No patients experienced ectropion, infection, bleeding or blindness.

Photographs and video of all patients who were clinically assessed were also obtained to clearly document normal extraocular movements. CT imaging confirmed the diagnosis of orbital floor fracture at the time of initial presentation in seven of the 11 patients. Four of the seven patients agreed to undergo a repeat scan to reassess the status of the fracture.

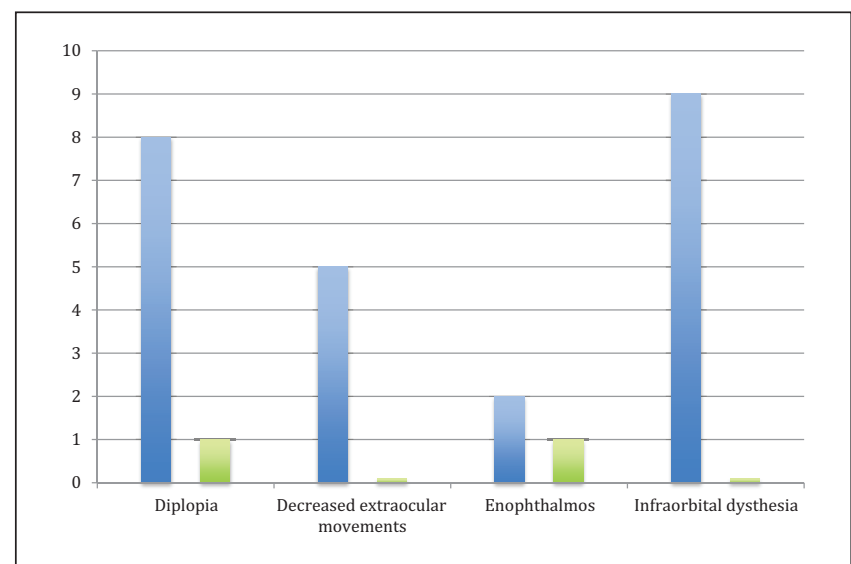

Figure 2) Number of patients with physical findings at time of initial presentation (blue) compared with at time of final assessment (green)

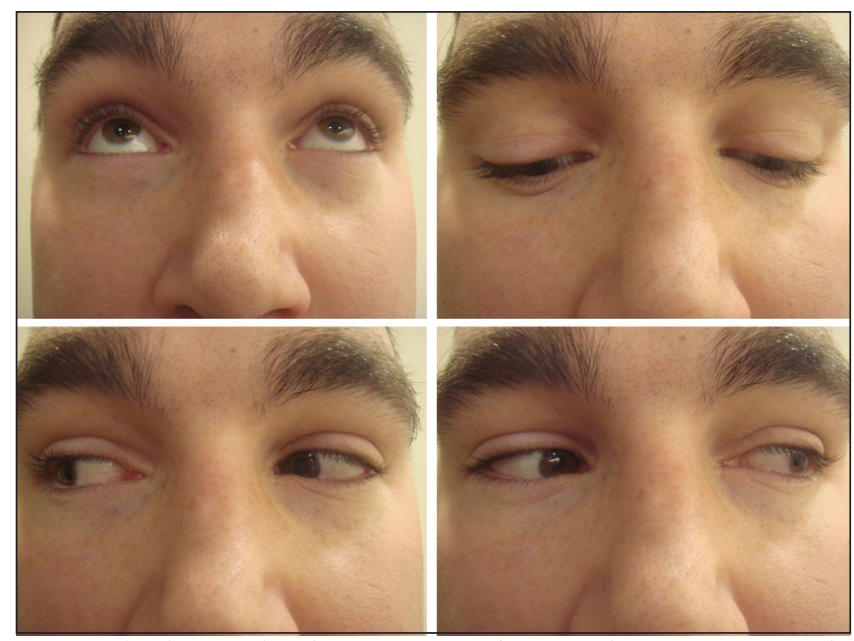

Figure 3) Photographic documentation of extraocular movements at the time of follow-up assessment more than four years after a right orbital floor fracture

\section{Case presentation}

A 24-year-old man sustained a right orbital floor fracture from a sporting accident. Four years after the original injury, the patient demonstrated full extraocular movements (Figure 3). CT scan images from the initial presentation were compared with corresponding images from a CT scan performed more than four years later (Figure 4). Three-dimensional images were also obtained at the fouryear follow-up (Figure 5).

\section{DISCUSSION}

The present study obtained the same findings as those of Putterman $(10,13,14)$, namely, if operating on orbital floor fractures is delayed by two weeks, swelling-induced diplopia resolves on its own. Diplopia is rarely due to inferior rectus muscle entrapment, and can easily be determined with a forced duction test. The surgeons in Saint John, New Brunswick, have more than 50 years of experience with this delayed immediate surgical approach. We have seen hundreds of cases of swelling-induced diplopia resolve without immediate surgery, and seldom need to operate on these patients. We have also seen what Putterman observed about enophthalmos - that most of it is asymptomatic. We believe that we have avoided unnecessary surgical and anesthetic risks to hundreds of patients by delaying surgery, as well as unnecessary operating room time and costs.

In the present study, we tried to identify and bring in for examination all of the patients with orbital floor fractures seen by the senior surgeon over a 10 -year period. We were able to locate and examine 

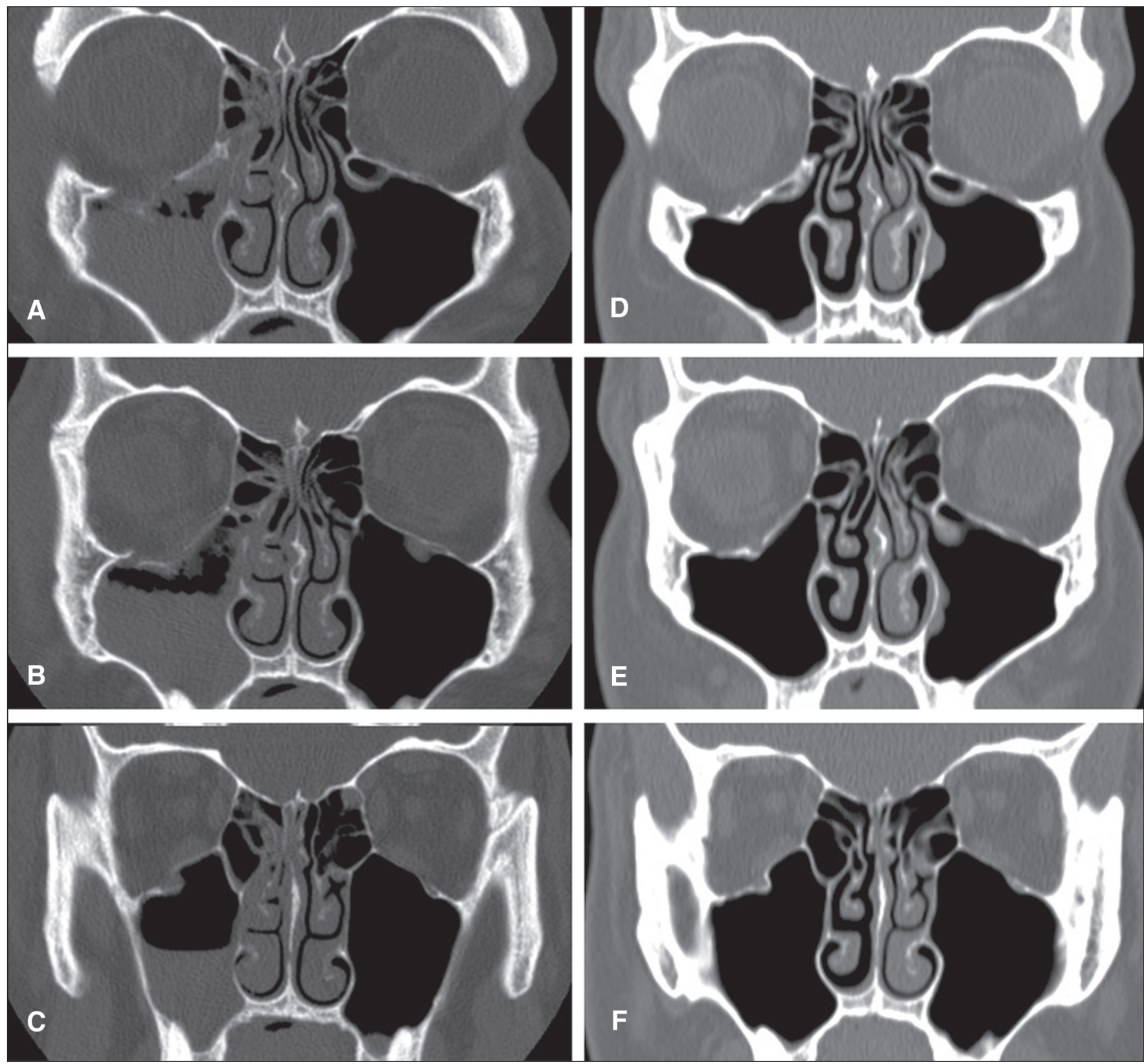

Figure 4) Comparative computed tomography scan images of a patient with a right orbital floor fracture. $\mathrm{A}$ to $\mathrm{C}$ are at initial presentation, $\mathrm{D}$ to $\mathrm{F}$ are at final follow-up assessment more than four years after the injury
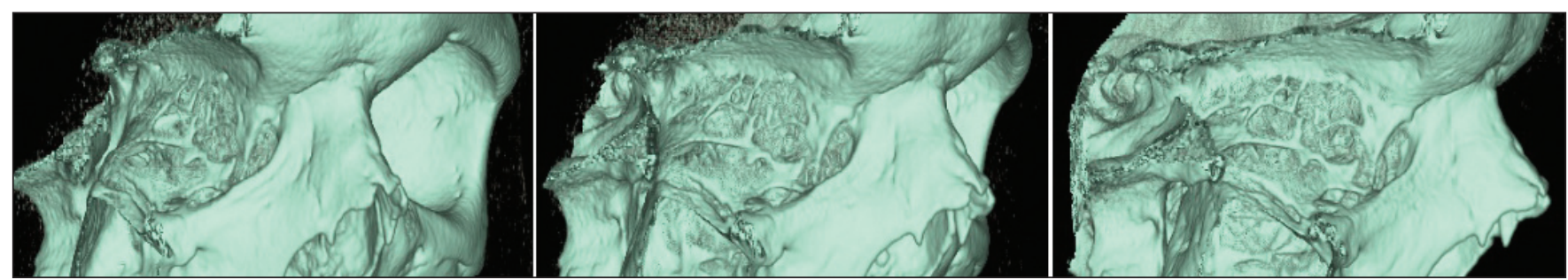

Figure 5) Three-dimensional computed tomography reconstructions of the orbital floor more than four years after the initial fracture (right side)

11 patients for late follow-up. Only one had persistent diplopia on extreme lateral gaze only, and it was not troublesome to the patient. One had a clinically visible enophthalmos measured at $-3 \mathrm{~mm}$, but it was asymptomatic and did not bother the patient. The remaining patients were asymptomatic, as most of our patients have been for the past 26 years. Surgery-induced complications such as scarring, ectropion, and other lid malpositions or dysfunction are naturally eliminated.
Surgeons have an inherent bias toward surgery, but operative fixation of orbital floor fractures is not without potential risk. Reported complications of orbital floor reconstruction include persistent ophthalmic dysfunction, ectropion (15), poor scarring, infection, implant extrusion and even blindness $(16,17)$. Given the propensity for orbital floor fractures to occur in a young, healthy population, with considerable rates of spontaneous resolution of ophthalmic symptoms, a more 
conservative management strategy may be appropriate for these patients. Losee et al (18) showed that conservative management of pediatric orbital floor fractures is warranted. It has been our experience that Losee et al's experiences with the pediatric population are similar to the adults that we encounter with this problem.

Accepted indications for immediate surgical repair include diplopia and unresolving oculocardiac reflex with CT evidence of muscle/ periorbita entrapment, 'white-eyed blow-out fractures', a large floor defect, and significant enophthalmos or hypoglobus causing facial asymmetry (19). In recent years, there has been a trend toward early exploration and aggressive operative restoration of the fractured orbital floor with various open (20) and endoscopic techniques (21). The reason for this is that late presentation of orbital floor fractures with enophthalmos, diplopia or hypoglobus can be difficult to treat (22). However, whether waiting two weeks before surgical treatment has a deleterious effect on the surgery or its results has never been properly addressed, and needs a good level I or II prospective study.

A clear weakness of the present study is the small sample size. Many patients suffer multiple facial fractures at the time of their injury, limiting the number of patients considered for the present study. In addition, the majority of potential subjects were excluded from the present study because of an inability to adequately follow up. As expected, this is a difficult population to reliably follow and include in any study. However, we believe it important to get this message out there before the natural history of unoperated orbital floors is forgotten. In this situation, the attempted surgical cure may, in fact, be worse than the natural history of the disease.

The present study provides level IV evidence in support of delaying immediate orbital floor surgery for up to two weeks to determine which patients will develop symptomatic enophthalmos or maintain persistent diplopia. We are hopeful that groups who believe in immediate surgery would perform a proper prospective study comparing immediate versus delayed immediate surgery.

NOTE: This article was presented at the Canadian Society of Plastic Surgeons meeting in Kelowna, British Columbia, in 2009. The authors have no financial dislcosures or conflicts of interest to declare.

\section{REFERENCES}

1. Yilmaz M, Vayvada H, Aydin E, Menderes A, Atabey A. Repair of fractures of the orbital floor with porous polyethylene implants. Br J Oral Maxillofac Surg 2007;45:640-4.

2. Cruz AA, Eichenberger GC. Epidemiology and management of orbital fractures. Curr Opin Ophthalmol 2004;15:416-21.

3. Schmäl F, Basel T, Grenzebach UH, Thiede O, Stoll W.

Preseptal transconjunctival approach for orbital floor fracture repair: Ophthalmologic results in 209 patients. Acta Otolaryngol 2006;126:381-9.
4. Folkestad L, Granstrom G. A prospective study of orbital fracture sequelae after change of surgical routines. J Oral Maxillofac Surg 2003;61:1038-44.

5. Gomes PP, Passeri LA, Barbosa JR. A 5-year retrospective study of zygomatico-orbital complex and zygomatic arch fractures in Sao Paulo State, Brazil. J Oral Maxillofac Surg 2006;64:63-7.

6. Tong L, Bauer RJ, Buchman SR. A current 10-year retrospective survey of 199 surgically treated orbital floor fractures in a nonurban tertiary care center. Plast Reconstr Surg 2001;108:612-21.

7. Ellis E 3rd, el-Attar A, Moos KF. An analysis of 2,067 cases of zygomatico-orbital fracture. J Oral Maxillofac Surg 1985;43:417-28.

8. Smith B, Regan WF Jr. Blow-out fracture of the orbit; mechanism and correction of internal orbital fracture. Am J Ophthalmol 1957:44:733-9.

9. Emery JM, Noorden GK, Sclernitzauer DA. Orbital floor fractures: Long-term follow-up of cases with and without surgical repair. Trans Am Acad Ophthalmol Otolaryngol 1971;75:802-12.

10. Putterman AM. Late management of blow-out fractures of the orbital floor. Trans Sect Ophthalmol Am Acad Ophthalmol Otolaryngol 1977;83:650-9.

11. Everhard-Halm YS, Koornneef L, Zonneveld FW. [Conservative therapy frequently indicated in blow-out fractures of the orbit.] Ned Tijdschr Geneeskd 1991;135:1226-8.

12. Catone GA, Morrissette MP, Carlson ER, A retrospective study of untreated orbital blow-out fractures. J Oral Maxillofac Surg 1988;46:1033-8.

13. Putterman AM, Stevens T, Urist MJ. Nonsurgical management of blow-out fractures of the orbital floor. Am J Ophthalmol 1974;77:232-9.

14. Putterman AM. Management of orbital floor blowout fractures. Adv Ophthalmic Plast Reconstr Surg 1987;6:281-5.

15. Ridgway EB, Chen C, Colakoglu S, Gautam S, Lee BT. The incidence of lower eyelid malposition after facial fracture repair: A retrospective study and meta-analysis comparing subtarsal, subciliary, and transconjunctival incisions. Plast Reconstr Surg 2009;124:1578-86.

16. Lederman IR. Loss of vision associated with surgical treatment of zygomatic-orbital floor fracture. Plast Reconstr Surg 1981;68:94-9.

17. McCartney DL, Char DH. Return of vision following orbital decompression after 36 hours of postoperative blindness. Am J Ophthalmol 1985;100:602-4.

18. Losee JE, Afifi A, Jiang S, et al. Pediatric orbital fractures: Classification, management, and early follow-up. Plast Reconstr Surg 2008;122:886-97.

19. Burnstine MA. Clinical recommendations for repair of orbital facial fractures. Curr Opin Ophthalmol 2003;14:236-40.

20. Salgarelli AC, Bellini P, Landini B, Multinu A, Consolo U. A comparative study of different approaches in the treatment of orbital trauma: An experience based on 274 cases. Oral Maxillofac Surg 2010;14:23-7.

21. Cheong EC, Chen CT, Chen YR. Broad application of the endoscope for orbital floor reconstruction: Long-term follow-up results. Plast Reconstr Surg 2010;125:969-78.

22. Antonyshyn O, Gruss JS, Kassel EE. Blow-in fractures of the orbit. Plast Reconstr Surg 1989;84:10-20. 